\title{
Effects of acid mine drainage on the genetic diversity and structure of a natural population of Daphnia longispina
}

\author{
Nelson Martins ${ }^{a, *}$, Catherine Bollinger ${ }^{b}$, Ruth M. Harper ${ }^{b}$, Rui Ribeiro $^{a}$ \\ a IMAR-Instituto do Mar, Department of Zoology, University of Coimbra, Largo Marquês de Pombal, P-3004 517 Coimbra, Portugal \\ ${ }^{\mathrm{b}}$ Department of Environmental Sciences, Western Washington University, Bellingham, WA 98225, USA
}

\section{A R T I C L E I N F O}

\section{Article history:}

Received 23 October 2008

Received in revised form 15 January 2009

Accepted 17 January 2009

\section{Keywords:}

Microevolution

Population genetics

Daphnia

Metals

AFLP

\begin{abstract}
A B S T R A C T
The increase in resistance to contaminants can result in the loss of genetic diversity of impacted populations. In this work, the effects of acid mine drainage (AMD) on the genetic diversity and structure of a historically exposed population of Daphnia longispina were evaluated using amplified fragment length polymorphism (AFLP) analysis. Individual sensitivity to acute copper exposure was determined in order to characterize the populations in terms of metal tolerance and in an attempt to identify possible contaminant indicative bands (CIB). No reduction in genetic diversity was found in the AMD impacted site population, in comparison to two reference populations. However, the analysis of molecular variance indicated a significant genetic differentiation from the two reference populations and a significant correlation between individual genetic distance and tolerance. The different average tolerance of individuals presenting one specific AFLP band indicated the existence of one putative CIB.
\end{abstract}

(C) 2009 Elsevier B.V. All rights reserved.

\section{Introduction}

The loss of genetic diversity in natural populations due to contaminants is one of the current concerns in environmental toxicology (Bagley et al., 2002). Genetic diversity is an important factor for the survival of populations (review in Bagley et al., 2002; Roark and Brown, 1996). Contaminants can affect the genetic structure of populations either directly, by increasing the mutation rates, or indirectly through population-mediated processes like selection or bottlenecks (higher level or emergent effects) (Belfiore and Anderson, 2001; Bickham et al., 2000).

Changes in the genetic structure of the population due to selection of resistant individuals and genetic bottlenecks have been studied for the last three decades (review in Belfiore and Anderson, 2001). The most common effect that follows the input of a contaminant is the increase in the overall tolerance of the population (e.g. Lopes et al., 2004, 2005). This increase in tolerance can be accompanied by: genetic diversity loss; genetic divergence from reference populations due to the increase in frequency of resistance determining (or closely linked) alleles or stochastic changes in population structure (e.g. Belfiore and Anderson, 2001; Theodorakis et al., 1999); or habitat fragmentation due to decreased migration rates (Bagley et al., 2002). These changes can lead to a decrease

\footnotetext{
* Corresponding author. Tel.: +351 239855781; fax: +351 239855789.

E-mail addresses: aa_nelsonmartin@student.biologia.uc.pt, nelson_m@netvisao.pt (N. Martins).
}

in population survival chances by altering life history parameters (Bagley et al., 2002; Belfiore and Anderson, 2001; Ward and Robinson, 2005) or by increasing susceptibility to future stressors (e.g. Belfiore and Anderson, 2001; Lewis et al., 2001; Ward and Robinson, 2005).

When the contaminants increase mutations rates this may cause an immediate increase in population genetic diversity. Given that mutations usually are slightly deleterious and accumulate in the genome, this gene pool change can lead to an increased mortality and/or a decreased reproduction rate and, ultimately, to population extinction (Bagley et al., 2002; Bickham et al., 2000). To confound our understanding of population level changes, the loss of genetic diversity caused by contaminant induced mutations can be masked or delayed by successful immigration or population recovery making field assessment of genetic changes challenging to identify (Theodorakis, 2001).

In the present study, the amplified fragment length polymorphism technique (AFLP) (Vos et al., 1995) was used to explore these effects in a natural population of Daphnia longispina. This methodology is, together with allozyme analysis, microsatellites, random amplification of polymorphic DNA (RAPD), mitochondrial DNA sequencing, and single nucleotide polymorphism detection, among the most common and recommended methodologies for population genetics analysis (Bagley et al., 2002; Belfiore and Anderson, 2001; Bickham et al., 2000). The main advantages are that AFLP produces large numbers of reproducible markers across the entire genome and no prior knowledge of the genome is required, thus eliminating the time and costs associated with marker devel- 
opment. The markers it generates are also variable enough to differentiate individuals at the intraspecific and intra-population level (Gili et al., 2004; Mueller and Wolfenbarger, 1999; Ward and Robinson, 2005). It has been successfully used in daphnids to identify species-specific markers and hybrid identification (Gili et al., 2004) and was used to quantify genetic variation in laboratory cultures and after artificial selection experiments (Ward and Robinson, 2005). This methodology also has the possibility of generating contaminant indicative bands (CIB) (Theodorakis et al., 1999). These bands are present in higher frequencies in contaminant tolerant populations and could be generated from, or linked to, loci responsible for increased tolerance to contamination (Theodorakis et al., 1999).

Daphnids are standard species in aquatic ecotoxicology research (e.g. OECD, 1998, 2004) and population genetic studies (e.g. King et al., 1995; Spaak and Ringelberg, 1997), given their functional importance in freshwater ecosystems, easy maintenance in the laboratory and cyclical parthenogenic reproduction, which allows both sexual recombination and long-term maintenance of clonal lineages in the laboratory (Colbourne et al., 2005). Evolution of tolerance (Limburg and Weider, 2002; Lopes et al., 2004, 2005), accompanied by rapid population changes either to metal contamination (Pollard et al., 2003) or other stressors (e.g. DeClerck et al., 2001; Hairston et al., 1999), has been reported, providing further support for the use of daphnids in this study.

The main objective of the current research was to evaluate the impacts of acid mine drainage (AMD) on the genetic diversity and structure of a historically exposed $D$. longispina population using AFLP markers. Furthermore, individual tolerance to lethal levels of copper was studied, so that a characterization in terms of tolerance of the individuals and populations could be obtained. Several authors stressed the importance of supplementing the differences in gene frequencies between populations with data showing direct evidence of differential fitness between individuals, such as time to death (TTD) (Belfiore and Anderson, 2001; Theodorakis et al., 1999). The TTD was also used in the identification of putative CIB.

\section{Materials and methods}

\subsection{Study site}

The aquatic system of the abandoned cupric-pyrite mine of São Domingos (SE Portugal; $37^{\circ} 40^{\prime} \mathrm{N}, 7^{\circ} 29^{\prime} \mathrm{W}$ ) was selected for this study. The abandoned mine tailings of this mine produce an acid mine drainage (AMD) effluent contaminated with the metals $\mathrm{Al}$, $\mathrm{Fe}, \mathrm{Zn}, \mathrm{Cu}, \mathrm{Mn}, \mathrm{Co}, \mathrm{Ni}, \mathrm{Cd}, \mathrm{Cr}, \mathrm{Pb}$, and As (in the range of 164-362, 90.8-350, 14.0-85.5, 17.9-38.0, 11.0-22.8, 1.07-2.41, 0.383-0.780, $0.048-0.740,0.0564-0.142,<0.100-0.254$, and $0.006-0.037 \mathrm{mg} / \mathrm{L}$, respectively) (Lopes et al., 1999), which is discharged into the Chança River reservoir, within the Guadiana River basin, Portugal. Three sites within this system were sampled: one contaminated with acid mine drainage (site I), after the confluence of the AMD effluent with a small subsidiary stream (Mosteirão stream); one upstream reference site within the same waterbody (site R), separated from site I by a direct distance of $3 \mathrm{~km}$ by land (water distance of $9.4 \mathrm{~km}$ ); and one reference site (RR) in an independent semiartificial lagoon, located $5.8 \mathrm{~km}$ from site I and $4.9 \mathrm{~km}$ from site R (Fig. 1). The coordinates and physico-chemical parameters of the sites at the time of organism collection are reported in Fig. 1.

\subsection{Field populations}

The $D$. longispina population from each study site was sampled on three different occasions, from April 25 to April 28, 2006. Collection of daphnids was done so that each population was sampled

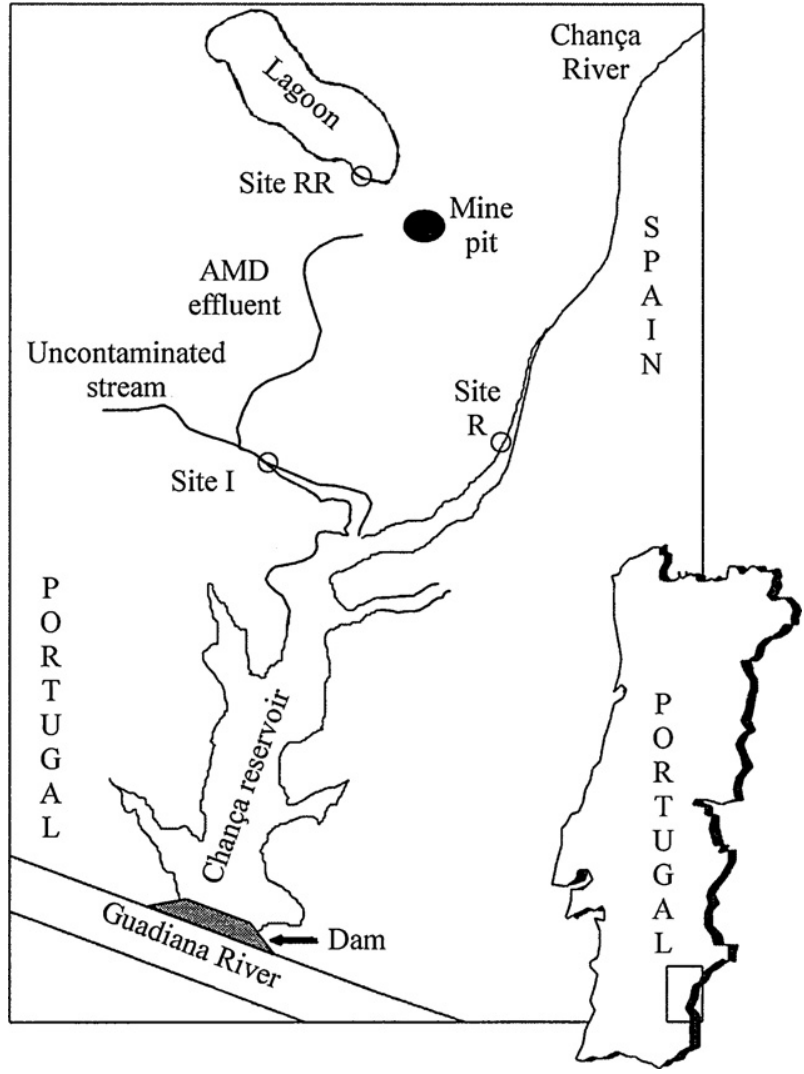

Fig. 1. Map of the S. Domingos mine system. Sampling sites of the three Daphnia longispina populations are indicated with open circles. Site parameters: Site I: $37^{\circ} 37^{\prime} \mathrm{N}, 7^{\circ} 30^{\prime} \mathrm{W}, \mathrm{pH} 6$, conductivity $=437 \mu \mathrm{S} / \mathrm{cm}$. Site R: $37^{\circ} 38^{\prime} \mathrm{N}, 7^{\circ} 28^{\prime} \mathrm{W}, \mathrm{pH} 7$, conductivity $=295 \mu \mathrm{S} / \mathrm{cm}$. Site RR: $37^{\circ} 40^{\prime} \mathrm{N}, 7^{\circ} 30^{\prime} \mathrm{W}, \mathrm{pH}$, conductivity $=272 \mu \mathrm{S} / \mathrm{cm}$.

three times (early morning, midday, and dusk), and on different days. The collection procedures followed those described by Lopes et al. $(2004,2005)$. At each site, one egg-bearing female was isolated from each net trawl. Net trawls were about $2 \mathrm{~m}$ apart from each other, except at site I where the total covered transect distance was about $50 \mathrm{~m}$ each sampling period. Approximately 120 individuals were collected during each sampling occasion, corresponding to a total of 360 individuals per population. Testing only individuals with eggs in the brood pouch ensured that only adult females were tested, that sex and life stage (juvenile versus adult) effects were minimized, and that the individuals were in a relatively good physiological state, since asexual reproduction in Daphnia is an indicator that no major physiological stressors are acting.

Organisms were subsequently taken to the laboratory and individually acclimated to American Society of Testing and Materials (ASTM) hard water (ASTM, 2002), without food or vitamins added, for $6 \mathrm{~h}$. The period of acclimation served to clear the digestive system and to reduce the variability in stress that the transfer to a different water medium could cause. Only individuals that were actively swimming after the acclimation period were tested.

\subsection{Tolerance to lethal levels of copper}

After the $6 \mathrm{~h}$ acclimation period, TTD tests were performed to determine tolerance of individuals to copper. A single concentration of $250 \mu \mathrm{g} / \mathrm{L}$ of copper was used. This value was expected to result in high mortality over the 48-h exposure period and was chosen based on previous work using organisms from the same sites (Lopes et al., 2004; Martins et al., 2007). Individuals were observed at regular time intervals during the period of the test: every $10 \mathrm{~min}$ during the first hour, every 15 min during the second hour, every 30 min 
until the 5 th hour, every hour until the 12 th hour, and every $2 \mathrm{~h}$ until the end of the test $(48 \mathrm{~h})$. Immediately after death, individuals were collected in Eppendorf tubes with $500 \mu \mathrm{L}$ of $99 \%$ ethanol and stored at $-20^{\circ} \mathrm{C}$ until DNA extraction.

\subsection{AFLP analysis}

The DNA extraction was done following the protocols by Reid et al. (2002) and Cousyn et al. (2001), with some minor changes. Briefly, after removing the ethanol, samples were homogenized in $30 \mu \mathrm{L}$ of $6 \%$ Chelex (Instagene DNA Purification Matrix, BIO-RAD, Amadora, Portugal) solution, incubated at $60^{\circ} \mathrm{C}$ for $1 \mathrm{~h}$, vortexed for $10 \mathrm{~s}$ at high speed, centrifuged for $3 \mathrm{~min}$ at $12000 \mathrm{rpm}$, and incubated at $99^{\circ} \mathrm{C}$ for $3 \mathrm{~min}$. The vortex and centrifugation were repeated and the samples were stored at $-20^{\circ} \mathrm{C}$ until AFLP analysis.

The AFLP analyses were performed following the LI-COR AFLP system instructions and, except when noted, all reagents and software used for AFLP analysis were acquired from LI-COR (Lincoln, NE, USA). This is a modified protocol of the standard AFLP method, as described by Vos et al. (1995), using infrared detection of marked nucleotides. An aliquot of total DNA (100 ng) was digested using 1.25 $\mathrm{U}$ MseI and $1.25 \mathrm{U}$ EcoRI in a $10 \mathrm{mM}$ Tris- $\mathrm{HCl}, 10 \mathrm{mM} \mathrm{Mg}{ }^{2+}$ and $50 \mathrm{mM} \mathrm{K}^{+}$buffer, in a $12.5 \mu \mathrm{L}$ reaction volume at $37^{\circ} \mathrm{C}$ for $2 \mathrm{~h}$. Restriction enzymes were inactivated, by incubating the mixture at $70^{\circ} \mathrm{C}$ for $15 \mathrm{~min}$, and ligation was carried out overnight at $20^{\circ} \mathrm{C}$, by adding $12 \mu \mathrm{L}$ of a mix of MseI and EcoRI adapters in ligation buffer ( $10 \mathrm{mM}$ Tris- $\mathrm{HCl}, 0.4 \mathrm{mM}$ ATP, $10 \mathrm{mM} \mathrm{Mg}^{2+}$ and $50 \mathrm{mM} \mathrm{K}^{+}$) and T4 DNA ligase (2.5 U). Ligation products were diluted 1:10 in nanopure water (Barnstead Nanopure Infinity UV System, Barnstead, Dubuque, IA, USA).

An aliquot of $2.5 \mu \mathrm{L}$ of the ligation mixture was used for preamplification PCR, which was performed in $25.5 \mu \mathrm{L}$ volumes with $2.5 \mu \mathrm{L} 10 \times$ PCR buffer (Roche Diagnostics, Indianapolis, IN, USA), $20 \mu \mathrm{L}$ of AFLP pre-amplification primer mix, containing dNTP's, MseI $+C$ and $\mathrm{EcoRI}+\mathrm{A}$ selective primers and $2.5 \mathrm{U}$ Taq polymerase (Roche). The PCR was carried out in an Eppendorf Mastercycler Gradient thermocycler (Eppendorf North America, Westbury, NY, USA) and consisted of 20 cycles of denaturing $\left(94^{\circ} \mathrm{C}, 30 \mathrm{~s}\right)$, annealing $\left(56^{\circ} \mathrm{C}, 1 \mathrm{~min}\right)$ and extension $\left(72^{\circ} \mathrm{C}, 1 \mathrm{~min}\right)$.

For selective amplification, preliminary trials using several primer combinations gave the best results using MseI + CAG or MseI + CAC and EcoRI + ACA or EcoRI + ACT primers. Selective amplification PCR was performed in $11 \mu \mathrm{L}$ volumes, using $2.0 \mu \mathrm{L}$ of $1: 40$ diluted pre-amplification product as template, $1.2 \mu \mathrm{L} 10 \times$ PCR buffer with $\mathrm{Mg}^{2+}, 2 \mu \mathrm{L}$ of MseI primer mix containing dNTPs, and $0.5 \mu \mathrm{L}$ of labeled EcoRI primer. EcoRI primers were labeled with IRD700 infrared dye. PCR consisted of 35 cycles of denaturation at $94^{\circ} \mathrm{C}(30 \mathrm{~s})$, annealling $(30 \mathrm{~s})$ and extension $\left(72^{\circ} \mathrm{C}, 1 \mathrm{~min}\right)$. Annealing temperatures decreased from 65 to $56^{\circ} \mathrm{C}$, in $0.7^{\circ} \mathrm{C}$ steps, between cycles 1 and 12 . Afterwards, PCR products were denatured for 3 min with $5.0 \mu \mathrm{L}$ Blue Stop Solution loading buffer at $94^{\circ} \mathrm{C}$, and immediately transferred to ice to avoid renaturation.

Electrophoresis and band detection was carried out on a LI-COR 4300 vertical electrophoresis system. Electrophoresis was run at $40 \mathrm{~W}, 1500 \mathrm{~V}, 40 \mathrm{~mA}$, and $45^{\circ} \mathrm{C}$, using $6.5 \% \mathrm{~KB}^{\text {Plus }}$ polyacrilamide gels in $25 \mathrm{~cm}$ plates. Band size determination and semi-automated band scoring was done using 50-700-base pairs fluorescent markers and SAGA-MX software.

\subsection{Data analysis}

Mean and median population sensitivities were calculated using Kaplan-Meier survival curves, to account for possible survivors after $48 \mathrm{~h}$ (censored cases), and compared via log-rank tests (SPSS, Version 12; SPSS, Chicago, IL, USA). Individuals were then divided in three to six tolerance groups, by evenly dividing the range of the log transformed survival times. Chi-square goodness of fit $\left(\chi^{2}\right)$ tests were performed to compare frequencies of individuals in the tolerance groups between populations.

For AFLP analysis, 31 individuals from each population were selected in a stratified random sampling design: from each population/tolerance category combination, a proportion of individuals corresponding to the frequency in the total population was randomly selected.

Given the dominant nature of AFLP data, allele frequencies were calculated according to the Taylor expansion of Lynch and Milligan (1994). Genetic diversity, quantified as Nei's genetic diversity index (Nei, 1973), observed heterozygosity and Shannon's information index were calculated with the software Popgen 32 (Version 1.32) (Yeh et al., 1997). These indices were then compared non-parametrically with Kruskal-Wallis tests and correlated nonparametrically with Spearman rank correlation with median TTD values (STATISTICA, Version 7, StatSoft, Tulsa, OK, USA). Nei's unbiased genetic distance and unweighted pair-group method using arithmetic averages (UPGMA) dendrograms based on these distances were calculated using the software Tools for Population Genetic Analyses (TFPGA, Version 1.3) (Miller, 1997). Richness, clonal diversity (King et al., 1995), evenness and Shannon's information indexes were also calculated for multilocus (clonal) genotypes in each population and tolerance group.

Genetic differentiation between populations or tolerance groups was evaluated via analysis of molecular variance (AMOVA) and exact tests of population differentiation (Rousset and Raymond, 1995). The first test, calculated based on the genetic distances between each individual (Huff et al., 1993), was performed using the methods implemented in the software package GenAlEx (Version 6) (Peakall and Smouse, 2006), whereas the second was done using TFPGA. A Mantel test relating individual genetic distances and TTD was performed using GenAlEx. Genetic distance between populations or tolerance groups, regarding multilocus genotypes, were calculated as described by King et al. (1995). To detect for possible CIB, locus-by-locus exact tests were performed in TFPGA and, for the bands that showed differentiation between the populations or tolerance groups, Kaplan-Meyer survival curves, log-rank tests and Cox regressions were used to compare survival times between genotypes, using the software SPSS. Cox regressions were used to compare median TTD of individual and combined genotypes of the bands that showed differences in TTD, accounting for possible interactive effects of the presence/absence of the bands and allowing for identification of the bands that contributed more to the observed differences.

\section{Results}

\subsection{Population tolerance characterization}

Mean and median TTD, both for the total number of tested individuals of each population and for the ones selected for AFLP analysis, are shown in Table 1 . The TTD differed significantly between populations (global log-rank, $p<0.001$ ).

Five groups of tolerance were defined when individuals were grouped according to their TTD: extremely sensitive, very sensitive (VS), sensitive (S), tolerant ( $\mathrm{T}$ ) and very tolerant (VT), with ranges of TTD's of $0 \mathrm{~min}$ to $30 \mathrm{~min}, 30 \mathrm{~min}$ to $1 \mathrm{~h} 30 \mathrm{~min}, 1 \mathrm{~h} 30 \mathrm{~min}$ to $4 \mathrm{~h}$ $30 \mathrm{~min}, 4 \mathrm{~h} 30 \mathrm{~min}$ to $14 \mathrm{~h}$, and $14 \mathrm{~h}$ to $48 \mathrm{~h}$ respectively. Division in three, four and six tolerance groups yielded less homogeneous distributions in the number of individuals among the categories, so the division in five groups was chosen. Given that the extremely sensitive group only contained 9 individuals out of the 1072 individuals tested in total (less than 1\%), we opted a posteriori, to group these 9 individuals with the VS group. Hereafter, the VS group refers to the 
Table 1

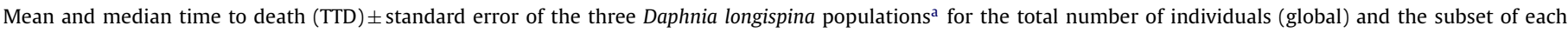
population in which amplified fragment length polymorphism analysis was performed (AFLP).

\begin{tabular}{|c|c|c|c|c|c|c|}
\hline & \multicolumn{3}{|l|}{ Global } & \multicolumn{3}{|l|}{ AFLP } \\
\hline & I & $\mathrm{R}$ & $\mathrm{RR}$ & I & $\mathrm{R}$ & $\mathrm{RR}$ \\
\hline$n$ & 357 & 354 & 361 & 31 & 31 & 31 \\
\hline Mean TTD & $\begin{array}{l}21 \mathrm{~h} 02 \mathrm{~min} \\
\pm 43 \mathrm{~min}\end{array}$ & $\begin{array}{l}5 \mathrm{~h} 13 \mathrm{~min} \\
\pm 28 \mathrm{~min}\end{array}$ & $\begin{array}{l}1 \mathrm{~h} 36 \mathrm{~min} \\
\pm 1 \mathrm{~min}\end{array}$ & $\begin{array}{l}22 \mathrm{~h} 58 \mathrm{~min} \\
\pm 3 \mathrm{~h} 07 \mathrm{~min}\end{array}$ & $\begin{array}{l}6 \mathrm{~h} 17 \mathrm{~min} \\
\pm 1 \mathrm{~h} 52 \mathrm{~min}\end{array}$ & $\begin{array}{l}1 \mathrm{~h} 30 \mathrm{~min} \\
\pm 7 \mathrm{~min}\end{array}$ \\
\hline Median TTD & $\begin{array}{l}18 \mathrm{~h} 00 \mathrm{~min} \\
\pm 1 \mathrm{~h} 06 \mathrm{~min}\end{array}$ & $\begin{array}{l}1 \mathrm{~h} 45 \mathrm{~min} \\
\pm 4 \mathrm{~min}\end{array}$ & $\begin{array}{l}1 \mathrm{~h} 30 \mathrm{~min} \\
\pm 2 \mathrm{~min}\end{array}$ & $\begin{array}{l}22 \mathrm{~h} 00 \mathrm{~min} \\
\pm 5 \mathrm{~h} 34 \mathrm{~min}\end{array}$ & $\begin{array}{l}1 \mathrm{~h} 45 \mathrm{~min} \\
\pm 15 \mathrm{~min}\end{array}$ & $\begin{array}{l}1 \mathrm{~h} 14 \mathrm{~min} \\
\pm 05 \mathrm{~min}\end{array}$ \\
\hline $\begin{array}{l}\text { Population diversity parameters } \\
\text { Nei's genetic diversity index } \\
\text { Observed heterozygosity } \\
\text { Shannon's information index }\end{array}$ & & & & $\begin{array}{l}0.37 \pm 0.16 \\
0.32 \\
0.54 \pm 0.22\end{array}$ & $\begin{array}{l}0.33 \pm 0.16 \\
0.30 \\
0.50 \pm 0.22\end{array}$ & $\begin{array}{l}0.38 \pm 0.08 \\
0.35 \\
0.56 \pm 0.09\end{array}$ \\
\hline $\begin{array}{l}\text { Clonal diversity parameters } \\
n \\
\text { \%Uniques } \\
\text { Clonal diversity } \\
\text { Clonal richness }\end{array}$ & & & & $\begin{array}{l}22 \\
54 \\
0.94 \\
6.12\end{array}$ & $\begin{array}{l}18 \\
39 \\
0.93 \\
4.95\end{array}$ & $\begin{array}{l}20 \\
45 \\
0.91 \\
5.53\end{array}$ \\
\hline
\end{tabular}

a I: Site I population, R: Site R population, RR: Site RR population; population diversity parameters (mean \pm standard deviation) and clonal diversity parameters ( $n$, number of distinct clones; \%unique, percentage of unique clones in each population) are shown for the AFLP subset.

Table 2

Mean and median time to death (TTD) \pm standard error of the four groups of different tolerance to copper of Daphnia longispina .

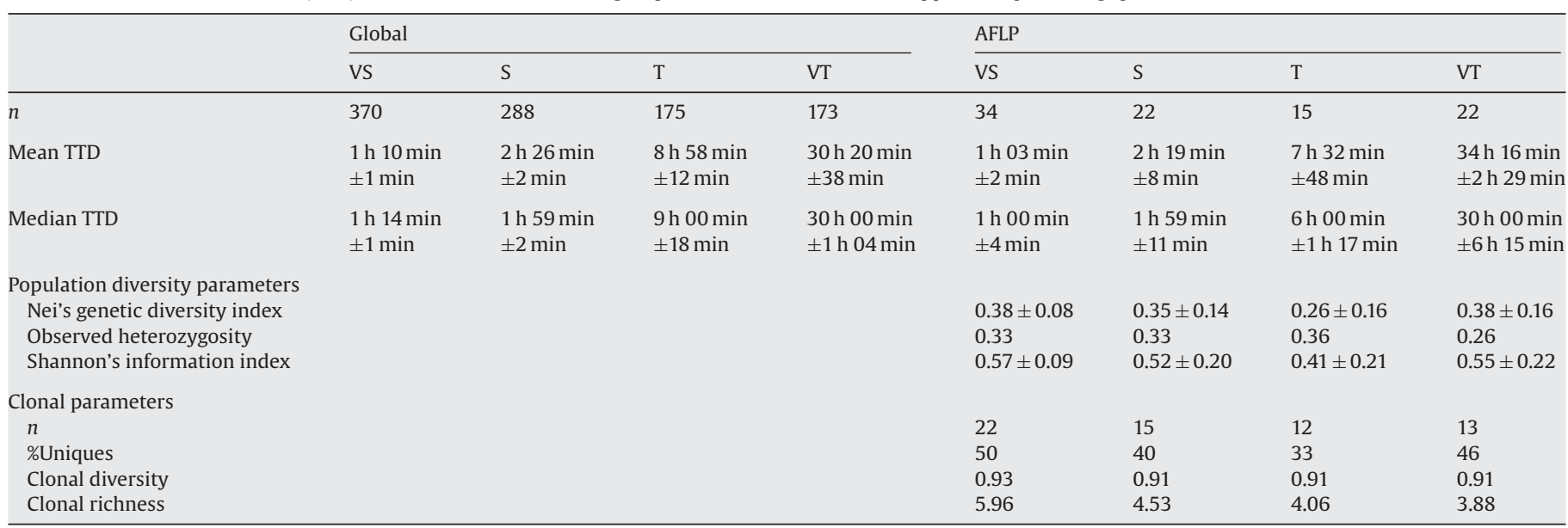

For the total number of individuals (Global) and the subset of each group on which amplified fragment length polymorphism analysis was performed (AFLP).

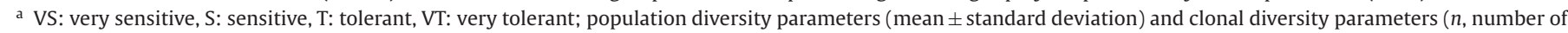
distinct clones; \%unique, percentage of unique clones in each population) are shown for the AFLP subset.

extremely sensitive and the very sensitive groups combined. The mean and median TTD for each group is presented in Table 2. The distribution of individuals from each population in each tolerance category was significantly different, either generally or between all populations pairs (Fig. $2 ; \chi^{2}, p<0.001$ globally and for all pairwise comparisons).

\subsection{Genetic diversity and differentiation}

Nei's genetic diversity, observed heterozygosity and Shannon's information index for each population are shown in Table 1. No differences were found for any of the calculated genetic diversity indices, either generally or between each pair of populations
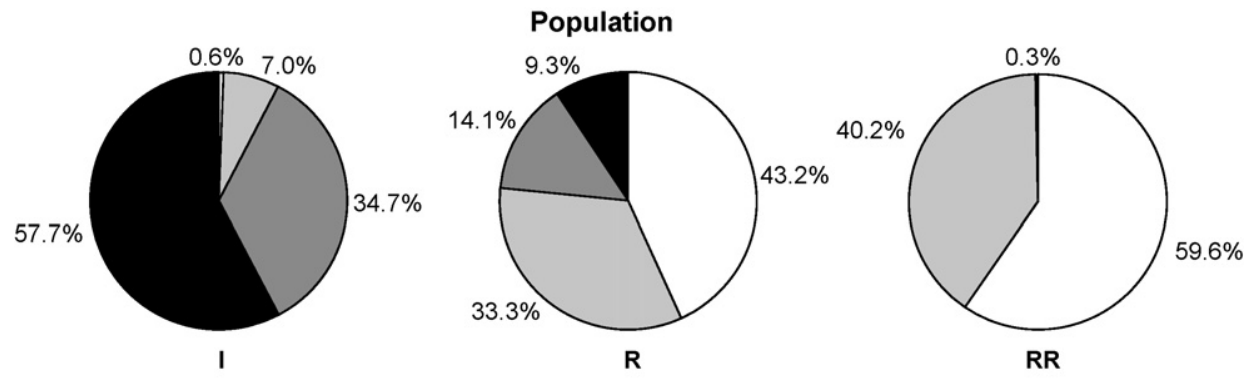

$\square$ vs

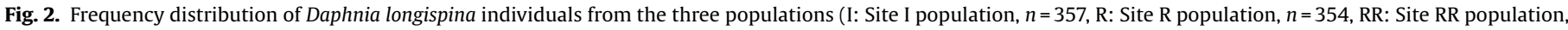
$n=361$ ) in groups of copper tolerance (VS: very sensitive, S: sensitive, T: tolerant, VT: very tolerant). 
Table 3

Nei's unbiased genetic distances (below diagonal) and clonal genetic distance (above diagonal) between the three populations of Daphnia longispina ${ }^{\text {. }}$.

\begin{tabular}{llll}
\hline & $\mathrm{I}$ & $\mathrm{R}$ & $\mathrm{RR}$ \\
\hline $\mathrm{I}$ & & 0.715 & 0.862 \\
$\mathrm{R}$ & $0.018^{*}$ & & 0.730 \\
$\mathrm{RR}$ & $0.015^{* *}$ & 0.008 & \\
\hline
\end{tabular}

a I: Site I population, R: Site R population, RR: Site RR population.

* $p$ of pairwise analysis of molecular variance $<0.05$.

${ }^{* *} p$ of pairwise analysis of molecular variance $<0.01$.

(Kruskal-Wallis, $p \geq 0.763$ ). Given that all the values were comparable, hereafter Nei's genetic diversity is used as the only measure of genetic diversity. The UPGMA dendrogram calculated based on Nei's unbiased genetic distance between populations (Table 3 ) is represented in Fig. 3. The AMOVA for differentiation of the populations was significant $(p=0.007)$. The I population was significantly different from the $\mathrm{R}$ and RR populations and no differences were found between the two reference populations (Table 3 ). The results of the exact tests also indicated significant differences $(p=0.006)$. Indexes regarding clonal genotype diversity show similar diversity levels between the three populations, with slightly higher percentage of unique clones and diversities in the I population (Table 1). However, no statistical analysis was possible to test the significance of the results. The clonal genetic distance between the populations is shown in Table 3. These results disagree with the average genetic distance results (Fig. 3 ) in that clonal frequency distribution in population $\mathrm{I}$ is more similar to population $\mathrm{R}$ than the two references between them. As with the population results, no differences were found in the genetic diversity of the tolerance groups (Table 2; Kruskal-Wallis, $p=0.206$ ). Regarding the clonal diversities, the VS group had the highest percentage of unique clones and clonal diversity values (Table 2). Again, statistical analysis of the latter results was not possible. No correlation was found between genetic diversity and median TTD (Spearman rank order correlation, $r=-0.11, p>0.05)$. However, the Mantel test relating the genetic distance between the individuals and the log-transformed TTD values was significant $(r=0.06, p=0.030)$. The UPGMA dendrogram based on Nei's unbiased genetic distance between the tolerance groups (Table 4) is represented in Fig. 4. Genetic distance data showed a grouping of the VS and S groups and a higher dissimilarity between the T and VT groups than between these groups and VS and S (Table 4). Similar results were obtained with clonal genetic distance data (Table 4). Both AMOVA and exact tests for differentiation showed significant genetic differentiation among tolerance groups (AMOVA, $p=0.002$; exact tests, $p<0.001$ ). Pairwise AMOVA $p$ values indicated that the VS and $\mathrm{S}$ groups had identical band frequencies and that both the T and VT groups were significantly different from every other tolerance group (Table 4).
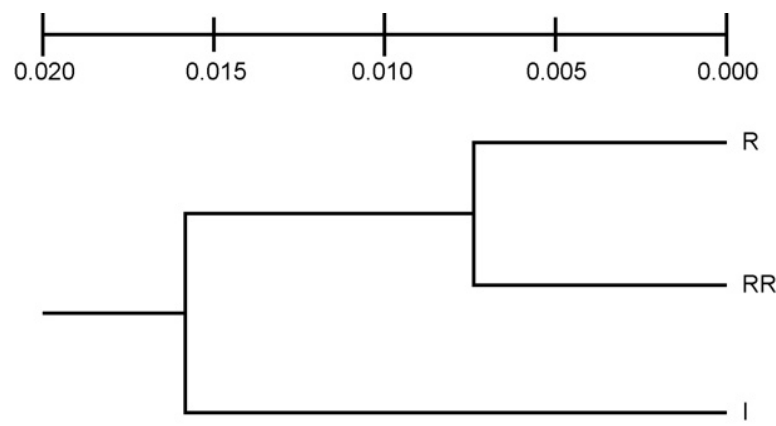

Fig. 3. Unweighted pair-group method using arithmetic averages dendrogram calculated from Nei's unbiased genetic distances of the three Daphnia longispina populations (I: Site I population, R: Site R population, RR: Site RR population).
Table 4

Nei's unbiased genetic distances (below diagonal) and clonal genetic distance (above diagonal) between the four groups of different tolerance to copper of Daphnia longispina ${ }^{\mathrm{a}}$.

\begin{tabular}{lllll}
\hline & VS & S & T & VT \\
\hline VS & & 0.650 & 0.718 & 0.905 \\
S & $<0.001$ & & 0.929 & 1.299 \\
T & $0.019^{*}$ & $0.026^{*}$ & & 1.805 \\
VT & $0.025^{* *}$ & $0.026^{* *}$ & $0.073^{* *}$ & \\
\hline
\end{tabular}

VS: Very sensitive, S: sensitive, T: tolerant, VT: very tolerant.

$p$ of pairwise analysis of molecular variance $<0.05$

$p$ of pairwise analysis of molecular variance $<0.01$.
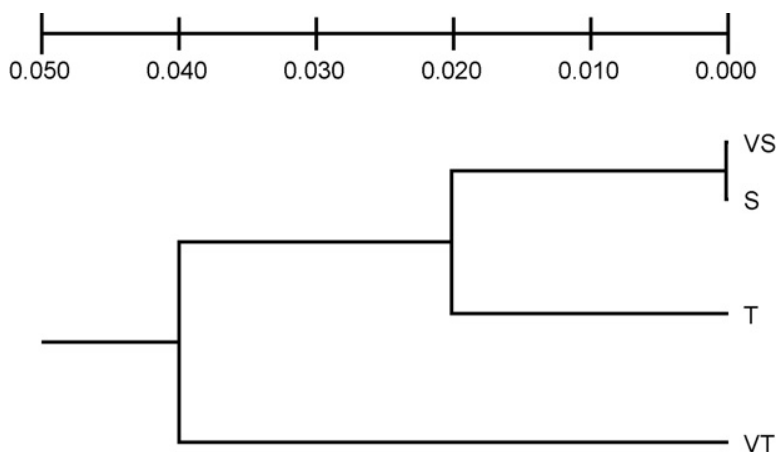

Fig. 4. Unweighted pair-group method using arithmetic averages dendrogram calculated from Nei's unbiased genetic distances of the four groups of different copper tolerance defined for Daphnia longispina (VS: very sensitive, S: sensitive, T: tolerant VT: very tolerant).

\subsection{Contaminant indicative bands}

According to the locus-by-locus tests of differentiation between the three populations, three bands were present in different frequencies: E-ACT-M-CAG-0091, E-ACA-M-CAG-0157 and E-ACAM-CAG-0188 (Table 5). When comparing the band frequencies of the two reference populations combined $(R+R R)$ with the I population, loci E-ACT-M-CAG-0091 and E-ACA-M-CAG-0188 differed between the two groups ( $p<0.001$ and $p=0.054$, respectively). Repeating this analysis with the different groups of tolerance, the bands E-ACT-M-CAG-0211 and E-ACT-M-CAG-0091 had different frequencies among the four groups of tolerance (Table 5). Relevant band frequencies in the groups and populations are shown in Table 6. Mean and median TTD of the individuals that

Table 5

Pairwise $p$ values for the identity of allele frequencies of amplified fragment length polymorphism (AFLP) bands with different global frequency distributions, between the three populations and four tolerance groups of Daphnia longispina ${ }^{\text {a }}$.

\begin{tabular}{|c|c|c|c|c|}
\hline & $\begin{array}{l}\text { E-ACT-M- } \\
\text { CAG-0091 }\end{array}$ & $\begin{array}{l}\text { E-ACA-M- } \\
\text { CAG-0157 }\end{array}$ & $\begin{array}{l}\text { E-ACA-M- } \\
\text { CAG-0188 }\end{array}$ & $\begin{array}{l}\text { E-ACT-M- } \\
\text { CAG-0211 }\end{array}$ \\
\hline \multicolumn{5}{|c|}{ In populations } \\
\hline I vs. $\mathrm{R}$ & 0.002 & - & 0.020 & - \\
\hline I vs. RR & 0.001 & - & - & - \\
\hline $\mathrm{R} v s . \mathrm{RR}$ & - & 0.020 & - & - \\
\hline Global & $<0.001$ & 0.048 & 0.035 & - \\
\hline \multicolumn{5}{|c|}{ In tolerance groups } \\
\hline VS vs. S & - & - & - & - \\
\hline VS vs. T & - & - & - & 0.010 \\
\hline VS vs. VT & 0.001 & - & - & 0.008 \\
\hline $\mathrm{S} v s . \mathrm{T}$ & - & - & - & - \\
\hline S vs. VT & 0.004 & - & - & 0.003 \\
\hline T vs. VT & 0.027 & - & - & $<0.001$ \\
\hline Global & 0.003 & - & - & $<0.001$ \\
\hline
\end{tabular}

a In populations: I: Site I population, R: Site R population, RR: Site RR population; in tolerance groups: VS: very sensitive, S: sensitive, T: tolerant, VT: very tolerant; $(-)$ : not significant $(p>0.05)$. 
Table 6

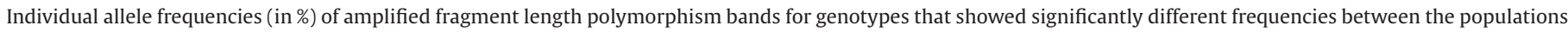
and groups of different tolerance to copper of Daphnia longispina, and mean and median time to death (TTD) of the genotype ( \pm standard error) ${ }^{\mathrm{a}}$.

\begin{tabular}{|c|c|c|c|c|c|c|c|c|}
\hline & \multicolumn{2}{|c|}{ E-ACT-M-CAG-0091 } & \multicolumn{2}{|c|}{ E-ACA-M-CAG-0157 } & \multicolumn{2}{|c|}{ E-ACA-M-CAG-0188 } & \multicolumn{2}{|c|}{ E-ACT-M-CAG-0211 } \\
\hline & 0 & 1 & 0 & 1 & 0 & 1 & 0 & 1 \\
\hline \multicolumn{9}{|l|}{ By population } \\
\hline I & 8.6 & 91.4 & 13.3 & 86.8 & 42.8 & 57.2 & 21.9 & 78.2 \\
\hline $\mathrm{R}$ & 42.9 & 57.1 & 0.0 & 100.0 & 50.2 & 49.8 & 16.1 & 83.9 \\
\hline $\mathrm{RR}$ & 41.7 & 58.3 & 6.7 & 93.3 & 35.3 & 64.7 & 22.3 & 77.7 \\
\hline \multicolumn{9}{|c|}{ By tolerance group } \\
\hline VS & 39.0 & 61.0 & 5.7 & 94.3 & 43.6 & 56.4 & 18.2 & 81.8 \\
\hline $\mathrm{S}$ & 38.0 & 62.1 & 3.9 & 96.2 & 28.7 & 71.3 & 26.0 & 74.0 \\
\hline $\mathrm{T}$ & 35.6 & 64.5 & 4.5 & 95.5 & 61.4 & 38.6 & 52.1 & 48.0 \\
\hline VT & 6.0 & 94.0 & 11.0 & 89.0 & 38.6 & 61.4 & 0.0 & 100.0 \\
\hline Mean TTD & $\begin{array}{l}3 \mathrm{~h} 56 \mathrm{~min} \\
\pm 1 \mathrm{~h} 14 \mathrm{~min}\end{array}$ & $\begin{array}{l}15 \mathrm{~h} 44 \mathrm{~min} \\
\pm 2 \mathrm{~h} 57 \mathrm{~min}\end{array}$ & $\begin{array}{l}13 \mathrm{~h} 27 \mathrm{~min} \\
\pm 5 \mathrm{~h} 05 \mathrm{~min}\end{array}$ & $\begin{array}{l}10 \text { h } 50 \mathrm{~min} \\
\pm 1 \text { h } 58 \mathrm{~min}\end{array}$ & $\begin{array}{l}10 \mathrm{~h} 46 \mathrm{~min} \\
\pm 2 \mathrm{~h} 05 \mathrm{~min}\end{array}$ & $\begin{array}{l}8 \mathrm{~h} 45 \mathrm{~min} \\
\pm 2 \mathrm{~h} 26 \mathrm{~min}\end{array}$ & $\begin{array}{l}3 \mathrm{~h} 30 \mathrm{~min} \\
\pm 34 \mathrm{~min}\end{array}$ & $\begin{array}{l}13 \mathrm{~h} 43 \mathrm{~min} \\
\pm 2 \mathrm{~h} 34 \mathrm{~min}\end{array}$ \\
\hline Median TTD & $\begin{array}{l}1 \text { h } 30 \text { min } \\
1 \text { h } 40 \text { min }\end{array}$ & $\begin{array}{l}4 \mathrm{~h} 59 \mathrm{~min} \\
\pm 1 \mathrm{~h} 52 \mathrm{~min}\end{array}$ & $\begin{array}{l}7 \mathrm{~h} 00 \mathrm{~min} \\
\pm 1 \mathrm{~h} 59 \mathrm{~min}\end{array}$ & $\begin{array}{l}6 \mathrm{~h} 43 \mathrm{~min} \\
\pm 23 \mathrm{~min}\end{array}$ & $\begin{array}{l}2 \mathrm{~h} 29 \mathrm{~min} \\
\pm 1 \mathrm{~h} 04 \mathrm{~min}\end{array}$ & $\begin{array}{l}1 \mathrm{~h} 59 \mathrm{~min} \\
\pm 15 \mathrm{~min}\end{array}$ & $\begin{array}{l}1 \mathrm{~h} 45 \mathrm{~min} \\
\pm 7 \mathrm{~min}\end{array}$ & $\begin{array}{l}1 \mathrm{~h} 59 \mathrm{~min} \\
\pm 50 \mathrm{~min}\end{array}$ \\
\hline
\end{tabular}

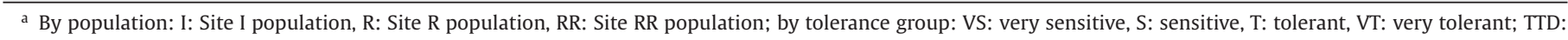
time to death; 0 : absent band, 1 : present band.

had different frequencies, either between populations or between groups of tolerance (E-ACT-M-CAG-0091, E-ACA-M-CAG-0188, EACA-M-CAG-0157, and E-ACT-M-CAG-0211), are also shown in Table 6.

The log-rank comparison of the TTD showed that individuals with the bands E-ACT-M-CAG-0091 or E-ACT-M-CAG-0211 had higher median TTD than individuals without these bands $(p<0.001$ and $p=0.025$, respectively), whereas individuals differing in the other two bands showed no differences $(p=0.674$ and $p=0.383$ for E-ACA-M-CAG-0157 and E-ACA-M-CAG-0188, respectively). The relative order of frequencies in the tolerance groups were VT $\gg \mathrm{T} \geq \mathrm{S} \geq \mathrm{VS}$ for E-ACT-M-CAG-0091 and $V T \gg V S \geq S \geq T$ for E-ACT-M-CAG-0211. The Cox regression analysis was significant for each band individually $(p=0.001$ and $p=0.036$ for E-ACT-M-CAG-0091 and E-ACT-M-CAG-0211, respectively). When the two bands were considered together, only the effect of the presence of the band E-ACT-M-CAG-0091 $(p=0.022)$ was significant, whereas neither the presence of the band $E$ ACT-M-CAG-0211 $(p=0.069)$ nor the interaction between them $(p=0.083)$ caused significant differences in the TTD of the individuals.

\section{Discussion}

Even though the reduction of genetic diversity in populations inhabiting contaminated areas has been reported in several aquatic and terrestrial species (Belfiore and Anderson, 2001; Bickham et al., 2000), recent studies employing either modern molecular methodologies, such as AFLP analysis (McMillan et al., 2006), microsatellite analysis (Berckmoes et al., 2005) and mitochondrial gene sequencing (Mulvey et al., 2003), or more classical methods, especially allozyme analysis (Mulvey et al., 2002; Roark et al., 2005) have found little or no evidence for this effect. Nevertheless, this possible effect is one of the major concerns of modern conservation biology and ecotoxicology (Bagley et al., 2002; van Straalen and Timmermans, 2002). To better evaluate the possible effects of AMD on the genetic diversity and structure of $D$. longispina populations and following the recommendations of other authors (Belfiore and Anderson, 2001; Theodorakis et al., 1999), an assessment of individual and population tolerance to acute copper contamination was done simultaneously with the genetic characterization of one population inhabiting a site impacted with AMD and two reference populations.

\subsection{Population tolerance characterization}

The current results on population tolerance are comparable to the ones obtained by Lopes et al. (2004) in the same aquatic system. These authors found that the range of individual genetically determined resistance of $D$. longispina to copper was larger in the reference than in the AMD impacted populations. This was due to the elimination of the most sensitive individuals at the impacted site, given that resistant individuals were found in the site $\mathrm{R}$ population, but no sensitive individuals were present in the site I population. Our current results showed that the tolerance distributions in the populations were similar to that of Lopes et al. (2004), even though a different mortality endpoint was used (TTD instead of NOEC of copper at $48 \mathrm{~h}$ ) (Fig. 2). In the present study, maternal effects and acclimation to elevated levels of metals as confounding variables at site I could not be totally eliminated. Such elimination could only be achieved if all the collected individuals were maintained for several generations in controlled and identical conditions, as cloned lineages, as done by Lopes et al. (2004). Robustness on the confirmation of the conclusions drawn by Lopes et al. (2004) was achieved here by increasing the number of tested individuals from each population (from approximately 130 to more than 350 individuals) and by adding another reference population (site RR). As in the above mentioned study, the site I population had a very low frequency of very sensitive $(0.6 \%)$ and a low frequency of sensitive individuals (7.0\%). The site R population showed a similar pattern of high frequency of very sensitive and sensitive individuals (76.6\%), and some tolerant ones (Fig. 2), when compared to the study by Lopes et al. (2004).

Comparing the two reference sites of the present study, almost no tolerant individuals were found in RR $(0.3 \%)$, while $23.4 \%$ of tolerant and very tolerant individuals were found in $\mathrm{R}$. These differences between the reference populations tolerance range could be due to the presence of another confounding factor that was unaccounted for or to natural variability. However, it is also possible that some resistant individuals have migrated (gene flow) from the site I population, since the I and R sites are in the same water body. Indeed, genetic differentiation was slightly more significant between I and $\operatorname{RR}(p=0.006)$ than between I and R populations $(p=0.019)$.

\subsection{Population genetic diversity and differentiation}

\subsubsection{Population genetic diversity}

Our current results indicated that, in the historically exposed D. longispina population (from site I), the reduction in the range of 
responses to lethal levels of copper was not related to a reduction in genetic diversity. Genetic diversity values found for the three studied populations were similar and within the range of other studies with Daphnia populations. Specifically, Nei's genetic diversity index in the present study ranged from $0.33 \pm 0.16$ to $0.36 \pm 0.08$ (mean \pm standard deviation) while other studies with Daphnia populations reported values of 0.22 (Haag et al., 2005, 2006) and from 0.10 to 0.50 (Weider and Hobaek, 2003). The values of observed heterozygosity here found ranged from 0.30 to 0.35 , which were within the range of reported values of $0.42 \pm 0.21$ to $0.59 \pm 0.28$ (Giessler, 1997) and from 0.20 to 0.32 (Limburg and Weider, 2002). Clonal diversity and genetic distance values were much higher than average diversity and distance calculated from single loci. This was due to the high number of different AFLP haplotypes found and high percentage of unique clones in each population.

Contrary to our current results, Ward and Robinson (2005) found that cadmium selection caused a significant reduction of the genetic diversity of a combination of 8 laboratory cultures of Daphnia magna Straus (from 0.21 to 0.07 ) and an increase in average cadmium tolerance from $50 \mu \mathrm{g} / \mathrm{L}$ to $200 \mu \mathrm{g} / \mathrm{L}$. No change in life history parameters was found when the cadmium selected population was grown under optimal laboratory conditions (except growth rates in the earlier life stages), so apparently the loss of genetic diversity did not cause a significant reduction in other important parameters for population survival. However, these authors did not identify if all the Daphnia cultures had the same life history parameters if grown independently, only reporting that they originally had different average cadmium tolerance (from 20 to over $120 \mu \mathrm{g} / \mathrm{L})$.

In the present study, maintenance of reference levels of genetic diversity in impacted populations could have been due to several factors, as discussed by other authors (McMillan et al., 2006; Mulvey et al., 2003; Weider, 1992), namely: (i) immigration from nearby reference populations and/or the diversity in the subjacent ephippial gene bank was high enough for the recovery of the diversity, (ii) the selection occurred at a limited number of genes, and the reduction of the diversity in these genes was not linked to a reduction in overall diversity; and/or (iii) the loss of genetic diversity due to contamination was of the same magnitude of the loss of diversity caused by clonal dominance in the reference populations. These hypotheses will be discussed separately in the following paragraphs.

In Daphnia and other facultative parthenogenic species, the ephippial egg-bank is the main genetic diversity reservoir and can maintain the genetic diversity of a population over a broad range of conditions, buffering the effects of seasonal, environmental, competition or contaminant-induced local extinction of genotypes (Brendonck and De Meester, 2003). The diversity of the egg-bank in a given period is directly related to the overlying adult population. However, several generations can overlap in the egg bank, and almost randomly emerge in each growing season (the probability of the hatching of an ephippium is inversely related to its age and its depth in the sediment, but mixing of the sediment can cause the older ephippia to become closer to the sediment surface than more recent ones). This overlapping of generations, concomitant with immigration from nearby populations either as adults or as epphipia (Figuerola et al., 2005), can be a powerful mechanism for the maintenance of diversity and can increase the population evolutionary potential on selection, resulting in a lowered risk of local extinction in the event of changing environmental conditions (Brendonck and De Meester, 2003).

As an example of the second hypothesis, Cousyn et al. (2001) found that, in daphnids, the genetic differentiation for ecologically relevant characters (measured as differentiation in the genetic component of the diel vertical migration response) was about ten times higher than for neutral markers (measured as microsatellite fre- quency variability), when comparing ephippia hatched individuals from periods of different predation pressure.

Regarding the third hypothesis, it was found (Weider, 1992) that intermediate to moderate levels of environmental disturbance in Daphnia populations were important to maintain the genetic diversity, given that, due to the parthenogenic mode of reproduction of these species, a small number of clones can quickly dominate a population in the absence of any selective pressure. These results are supported by the fact that lakes with permanent daphnid populations show less diversity and larger deviations from Hardy-Weinberg equilibrium than lakes with intermittent populations (i.e., when no individuals survive the winter and all the new individuals come either from immigration or from the ephippial egg bank produced at the end of the parthenogenic growing season) (Cerny and Hebert, 1993). Ward and Robinson (2005) found that, after only eight generations of strictly parthenogenic reproduction under optimal laboratory conditions, genetic diversity of $D$. magna was halved (Nei's genetic diversity index was reduced from 0.21 to 0.09 ) when no selective pressure was applied, while it was less significantly reduced (from 0.21 to 0.17 ) if a neutral pressure of $50 \%$ reduction in population size was applied at each generation.

\subsubsection{Population genetic differentiation}

A significant genetic differentiation was found between the AMD impacted population and the two reference populations, but no differentiation was found between the two reference populations (AMOVA tests). Furthermore, a significant correlation was found between individual genetic distances and TTD values (Mantel test). This could indicate that metal contamination acted as a directional selective pressure to change gene frequencies in the exposed population (site I) relative to the references, but this change in frequencies was not reflected by a loss of genetic diversity. These results are in agreement with some of the mentioned studies, which also found that the genetic differentiation between populations of fish (McMillan et al., 2006; Mulvey et al., 2002, 2003; Roark et al., 2005) and wood-mouse (Berckmoes et al., 2005) was more correlated with environmental contamination than with geographical distance and that these changes reflected selection by contaminants (Ownby et al., 2002).

\subsubsection{Copper tolerance groups}

Regarding the different copper tolerance groups, no differences in the average genetic diversity of each group was found (Kruskal-Wallis test), i.e., no group was statistically less genetically diverse or more homogeneous than the other. Allele frequencies in the very sensitive (VS) and sensitive (S) groups were very similar and frequencies of the tolerant (T) and very tolerant (VT) groups were significantly different from both the VS and S groups and between them (Table 4). The UPGMA clustering separated the VT group from the other three groups and an agreement between the group tolerance ranking and the increasing degree of differentiation between the groups (both according the AMOVA and UPGMA) was found. Furthermore, the results showed a higher degree of genetic differentiation between the tolerance groups than between the populations, given that the maximum branch length for the groups dendrogram was over 0.040 and for the populations was below 0.020 (Figs. 3 and 4).

\subsection{Contaminant indicative bands}

Regarding the possible existence of bands more frequent in the historically exposed population or in the more tolerant individuals (CIB), the E-ACT-M-CAG-0091 band was present in higher frequency both in the VT group and in the I population and the mean and median TTD of individuals that presented this band was also significantly higher than in individuals without this band 
(log-rank test). Besides E-ACT-M-CAG-0091, the band E-ACT-MCAG-0211 also had different frequencies between the four tolerance groups and, when considered alone, individuals with this band had a median survival time higher than the individuals without it. However, when both bands (E-ACT-M-CAG-0091 and E-ACT-MCAG-0211) were considered simultaneously, the effect of the second was not significant (Cox regression, $p=0.069$ ), neither was the interaction between them (Cox regression, $p=0.083$ ). Furthermore, the pattern of genetic frequencies was not so clear in E-ACT-M-CAG0211, given that its frequency significantly decreased between the VS, $\mathrm{S}$ and $\mathrm{T}$ groups and increased in the VT individuals, when compared to E-ACT-M-CAG-0091, which was increasingly more abundant when moving up in the tolerance ranking. Given these results, it is probable that only E-ACT-M-CAG-0091 is a putative CIB. This putative CIB could be amplified from, or be closely linked to, loci that are involved in metal tolerance. For instance, the higher frequency of this band in resistant individuals could be due to variations in metallothionein genes (Tanguy and Moraga, 2001; van Straalen and Timmermans, 2002), or to variations in other proteins, whose genotypes or phenotypes were found to be associated with differential tolerance to environmental contaminants in several species. For instance, specific asparatate aminotransferase, phosphoglucomutase and adenilate kinase genotypes were associated with differential survival under tributylin exposure (Tanguy et al., 1999). Furthermore, a consistent relationship between glucose-6-phosphate isomerase genotypes and response to several environmental stressors, including metals, has been shown (review in Tatara et al., 2001). Contaminant indicative bands, derived from RAPD analysis, were also found in populations inhabiting radionuclide-contaminated lakes and in artificial selection experiments by the same contaminants (Theodorakis et al., 1998, 1999). As the former authors pointed out, it is possible that these bands could not be directly related to the toxic mode of action, being contaminant-specific or always indicative of contaminant exposure, given that they were a result of random whole genome surveys and could have appeared only due to the probabilistic nature of both methodologies (i.e., AFLP and RAPD).

Therefore, the complete molecular characterization (sequencing, copy number) of the putative CIB found here, would be essential to correctly assess its possible relationship with the increased tolerance and its possible use as a biomarker in future field studies with D. longispina (Theodorakis, 2001). The current work being developed in Daphnia, whose genome is under active investigation (Colbourne et al., 2005; http://daphnia.cgb.indiana.edu/), is of great importance for the fulfillment of this last objective.

\section{Conclusion}

Even though a reduction in genetic diversity was not found in the impacted site population, it was possible to discriminate the impacted population from the reference populations based on altered gene frequencies and information on individual tolerance. Therefore the use of genetic diversity indices as the sole measure of impact in a population gene pool can be suspect and additional information (individual fitness, physico-chemical parameters, several reference and/or impacted populations) to draw valid conclusions is important. Furthermore, in the case of daphnids, where a big source for genetic diversity always exists in the form of resting eggs (Brendonck and De Meester, 2003) and recolonization is usually in the time span of a few years (Pollard et al., 2003), the loss of genetic diversity is not a cause of immediate concern for local population survival. A possible CIB, present in higher frequencies in tolerant individuals and in the population inhabiting the metal contaminated site was found. The identification of the origin of this band would be important for its establishment as a possible biomarker of exposure and effect, at the population level.

\section{Acknowledgements}

N. Martins was a recipient from a Ph.D. grant from Fundação para a Ciência e a Tecnologia (Portugal). The authors would also like to acknowledge I. Lopes and M. Moreira-Santos for the invaluable help in the field work and proofreading the article.

\section{References}

American Society of Testing and Materials (ASTM), 2002. Standard guide for conducting acute toxicity tests on test materials with fishes, microinvertebrates, and amphibians. Annual Book of ASTM Standards, vol. 1105. American Society of Testing and Materials, Philadelphia, PA, USA, pp. 729-796.

Bagley, M.J., Franson, S.E., Christ, S.A., Waits, E.R., Toth, G.P., 2002. Genetic Diversity as an Indicator of Ecosystem Condition and Sustainability: Utility for Regional Assessment of Streams in the Eastern United States. U.S. Environmental Protection Agency, Cincinnati, OH, USA.

Belfiore, N.M., Anderson, S.L., 2001. Effects of contaminants on genetic patterns in aquatic organisms: a review. Mutat. Res. 489, 97-122.

Berckmoes, V., Scheirs, J., Jordaens, K., Blust, R., Backeljau, T., Verhagen, R., 2005. Effects of environmental pollution on microsatellite DNA diversity in wood mouse (Apodemus sylvaticus) populations. Environ. Toxicol. Chem. 24, 2898-2907.

Bickham, J.W., Sandhu, S., Hebert, P.D.N., Chikhi, L., Athwal, R., 2000. Effects of chemical contaminants on genetic diversity in natural populations: implications for biomonitoring and ecotoxicology. Mutat. Res. 463, 33-51.

Brendonck, L., De Meester, L., 2003. Egg banks in freshwater zooplankton: evolutionary and ecological archives in the sediment. Hydrobiologia 491, 65-84.

Cerny, M., Hebert, P.D.N., 1993. Genetic diversity and breeding system variation in Daphnia pulicaria from North-American lakes. Heredity 71, 497-507.

Colbourne, J.K., Singan, V.R., Gilbert, D.G., 2005. wFleaBase: the Daphnia genome database. BMC Bioinformatics 6, 45.

Cousyn, C., De Meester, L., Colbourne, J.K., Brendonck, L., Verschuren, D., Volckaert, F., 2001. Rapid, local adaptation of zooplankton behavior to changes in predation pressure in the absence of neutral genetic changes. Proc. Natl. Acad. Sci. U.S.A. $98,6256-6260$.

DeClerck, S., Cousyn, C., De Meester, L., 2001. Evidence for local adaptation in neighbouring Daphnia populations: a laboratory transplant experiment. Freshwater Biol. 46, 187-198.

Figuerola, J., Green, A.J., Michot, T.C., 2005. Invertebrate eggs can fly: evidence of waterfowl-mediated gene flow in aquatic invertebrates. Am. Nat. 165, 274-280.

Giessler, S., 1997. Gene flow in the Daphnia longispina hybrid complex (Crustacea, Cladocera) inhabiting large lakes. Heredity 79, 231-241.

Gili, M., Monaghan, M.T., Spaak, P., 2004. Amplified fragment length polymorphism (AFLP) reveals species-specific markers in the Daphnia galeata-hyalina species complex. Hydrobiologia 526, 63-71.

Haag, C.R., Riek, M., Hottinger, J.W., Pajunen, V.I., Ebert, D., 2005. Genetic diversity and genetic differentiation in Daphnia metapopulations with subpopulations of known age. Genetics 170, 1809-1820.

Haag, C.R., Riek, M., Hottinger, J.W., Pajunen, V.I., Ebert, D., 2006. Founder events as determinants of within-island and among-island genetic structure of Daphnia metapopulations. Heredity 96, 150-158.

Hairston, N.G., Lampert, W., Caceres, C.E., Holtmeier, C.L., Weider, L.J., Gaedke, U., Fischer, J.M., Fox, J.A., Post, D.M., 1999. Lake ecosystems: rapid evolution revealed by dormant eggs. Nature 401, 446.

Huff, D.R., Peakall, R., Smouse, P.E., 1993. RAPD variation within and among naturalpopulations of outcrossing buffalograss [Buchloe dactyloides (Nutt.) Engelm.]. Theor. Appl. Genet. 86, 927-934.

King, C.E., Miracle, M.R., Vicente, E., 1995. Large Hardy-Weinberg equilibrium deviations in the Daphnia longispina of lake El Tobar. Hydrobiologia 307, 15-23.

Lewis, S.S., Klerks, P.L., Leberg, P.L., 2001. Relationship between allozyme genotype and sensitivity to stressors in the western mosquitofish Gambusia affinis detected for elevated temperature but not mercury. Aquat. Toxicol. 52, 205-216.

Limburg, P.A., Weider, L.J., 2002. 'Ancient' DNA in the resting egg bank of a microcrustacean can serve as a palaeolimnological database. Proc. R. Soc. Lond. B Biol. 269, 281-287.

Lopes, I., Gonçalves, F., Soares, A.M.V.M., Ribeiro, R., 1999. Discriminating the ecotoxicity due to metals and to low $\mathrm{pH}$ in acid mine drainage. Ecotoxicol. Environ. Saf. 44, 207-214.

Lopes, I., Baird, D.J., Ribeiro, R., 2004. Genetic determination of tolerance to lethal and sublethal copper concentrations in field populations of Daphnia longispina. Arch. Environ. Contam. Toxicol. 46, 43-51.

Lopes, I., Baird, D.J., Ribeiro, R., 2005. Resistance to metal contamination by historically stressed populations of Ceriodaphnia pulchella: environmental influence versus genetic determination. Chemosphere 61, 1189-1197.

Lynch, M., Milligan, B.G., 1994. Analysis of population genetic structure with RAPD markers. Mol. Ecol. 3, 91-99.

Martins, N., Lopes, I., Harper, R.M., Ross, P., Ribeiro, R., 2007. Differential resistance to copper and mine drainage in Daphnia longispina: relationship with allozyme genotypes. Environ. Toxicol. Chem. 26, 1904-1909. 
McMillan, A.M., Bagley, M.J., Jackson, S.A., Nacci, D.E., 2006. Genetic diversity and structure of an estuarine fish (Fundulus heteroclitus) indigenous to sites associated with a highly contaminated urban harbor. Ecotoxicology 15, 539-548.

Miller, M.P., 1997. Tools for population genetic analyses (TFPGA) 1.3: a Windows program for the analysis of allozyme and molecular population genetic data. Computer software distributed by author.

Mueller, U.G., Wolfenbarger, L.L., 1999. AFLP genotyping and fingerprinting. Trends Ecol. Evol. 14, 389-394.

Mulvey, M., Newman, M.C., Vogelbein, W., Unger, M.A., 2002. Genetic structure of Fundulus heteroclitus from PAH-contaminated and neighboring sites in the Elizabeth and York Rivers. Aquat. Toxicol. 61, 195-209.

Mulvey, M., Newman, M.C., Vogelbein, W.K., Unger, M.A., Ownby, D.R., 2003. Genetic structure and mtDNA diversity of Fundulus heteroclitus populations from polycyclic aromatic hydrocarbon-contaminated sites. Environ. Toxicol. Chem. 22, 671-677.

Nei, M., 1973. Analysis of gene diversity in subdivided populations. Proc. Natl. Acad. Sci. U.S.A. 70, 3321-3323.

OECD, 1998. Daphnia magna reproduction test. Test Guideline 211. Organization for Economic Cooperation and Development, Paris, France.

OECD, 2004. Daphnia sp. acute immobilisation test. Test Guideline 202. Organization for Economic Cooperation and Development, Paris, France.

Ownby, D.R., Newman, M.C., Mulvey, M., Vogelbein, W.K., Unger, M.A., Arzayus, L.F. 2002. Fish (Fundulus heteroclitus) populations with different exposure histories differ in tolerance of creosote-contaminated sediments. Environ. Toxicol. Chem. 21, 1897-1902.

Peakall, R., Smouse, P.E., 2006. GENALEX 6: genetic analysis in Excel. Population genetic software for teaching and research. Mol. Ecol. Notes 6, 288-295.

Pollard, H.G., Colbourne, J.K., Keller, W., 2003. Reconstruction of centuries-old Daphnia communities in a lake recovering from acidification and metal contamination. Ambio 32, 214-218.

Reid, V.A., Carvalho, G.R., George, D.G., Griffiths, H.I., 2002. A technique for the molecular genetic analysis of Daphnia resting eggs from sub-recent lake sediments. J. Paleolimnol. 27, 481-486.

Roark, S., Brown, K., 1996. Effects of metal contamination from mine tailings on allozyme distributions of populations of great plains fishes. Environ. Toxicol. Chem. 15, 921-927.

Roark, S.A., Nacci, D., Coiro, L., Champlin, D., Guttman, S.I., 2005. Population genetic structure of a nonmigratory estuarine fish (Fundulus heteroclitus) across a strong gradient of polychlorinated biphenyl contamination. Environ. Toxicol. Chem. 24 $717-725$.
Rousset, F., Raymond, M., 1995. Testing heterozygote excess and deficiency. Genetics 140, 1413-1419.

Spaak, P., Ringelberg, J., 1997. Differential behaviour and shifts in genotype composition during the beginning of a seasonal period of diel vertical migration. Hydrobiologia 360, 177-185.

Tanguy, A., Moraga, D., 2001. Cloning and characterization of a gene coding for a novel metallothionein in the Pacific oyster Crassostrea gigas (CgMT2): a case of adaptive response to metal-induced stress? Gene 273, 123-130.

Tanguy, A., Castro, N.F., Marhic, A., Moraga, D., 1999. Effects of an organic pollutant (tributyltin) on genetic structure in the pacific oyster Crassostrea gigas. Mar. Pollut. Bull. 38, 550-559.

Tatara, C.P., Newman, M.C., Mulvey, M., 2001. Effect of mercury and GPI-2 genotype on standard metabolic rate of eastern mosquitofish (Gambusia holbrooki). Environ. Toxicol. Chem. 20, 782-786.

Theodorakis, C.W., 2001. Integration of genotoxic and population genetic endpoints in biomonitoring and risk assessment. Ecotoxicology 10, 245-256.

Theodorakis, C.W., Bickham, J.W., Elbl, T., Shugart, L.R., Chesser, R.K., 1998 Genetics of radionuclide-contaminated mosquitofish populations and homology between Gambusia affinis and G. holbrooki. Environ. Toxicol. Chem. 17, 1992-1998.

Theodorakis, C.W., Elbl, T., Shugart, L.R., 1999. Genetic ecotoxicology. IV. Surviva and DNA strand breakage is dependent on genotype in radionuclide-exposed mosquitofish. Aquat. Toxicol. 45, 279-291.

van Straalen, N.M., Timmermans, M.J.T.N., 2002. Genetic variation in toxicantstressed populations: an evaluation of the "genetic erosion" hypothesis. Hum. Ecol. Risk Assess. 8, 983-1002.

Vos, P., Hogers, R., Bleeker, M., Reijans, M., van de Lee, T., Hornes, M., Frijters, A. Pot, J., Peleman, J., Kuiper, M., Zabeau, M., 1995. AFLP: a new technique for DNA fingerprinting. Nucleic Acids Res. 23, 4407-4414.

Ward, T.J., Robinson, W.E., 2005. Evolution of cadmium resistance in Daphnia magna. Environ. Toxicol. Chem. 24, 2341-2349.

Weider, L.J., 1992. Disturbance, competition and the maintenance of clonal diversity in Daphnia pulex. J. Evol. Biol. 5, 505-522.

Weider, L.J., Hobaek, A., 2003. Glacial refugia, haplotype distributions, and clona richness of the Daphnia pulex complex in arctic Canada. Mol. Ecol. 12, 463-473.

Yeh, F.C., Yang, R.-C., Boyle, T.B.J., Ye, Z.-H., Mao, J.X., 1997. POPGENE, The User-friendly Shareware for Population Genetic Analysis. Molecular Biology and Biotechnology Centre, University of Alberta, Edmonton, Alberta, Canada. 